\title{
線形構造化システムの可同定性に関する考察
}

\author{
早 川, 義 一*・細 江 繁 幸*・林 \\ 睦**・伊 藤 正 美*
}

\section{A Study of Structural Identifiability of Linear Systems}

\author{
Yoshikazu Hayakawa*, Shigeyuki Hosoe*, Mutsumi Hayashi* and Masami Ito*
}

\begin{abstract}
In many modeling problems, the system matrices have a number of fixed zero entries determined by the physical structure of the system while the remaining entries are a priori known functions of the free (physical) parameters. Then, from input-output data (e. g. transfer function), can we uniquely determine the unknown free parameters? This problem introduced the concept of structural identifiability (abbreviated to SI).

This paper discusses SI of the system whose parametrization is affine. Firstly we remark the relation between SI and the structural controllability (and observability), and give new algebraic equivalent conditions for SI. Based upon these results, secondly, we obtain all the SI structured systems the indeterminate entries of that are unrelated, and it is made clear how SI of compartmental systems is influenced by the way of connection among its subsystems.
\end{abstract}

Keyword: structural identifiability, structured system, compartmental system, coates graph, compartmental graph

\section{1. まえがき}

適当な物理量を状態変数に選び状態方程式を記述す る之, システムの構造的・物理的要求加, 状態方程 式の係数行列はある定まった位置に零に固定された要 素 (零固定要素) をむち，ほかの要素(非零固定要素) はある独立なパラメータ（たとえば，質量, 静電容量 などの物理パラメータ）の関数になる.

このとき, システムの構造（すなわち, 係数行列に おける零固定要素の位置および非零固定要素の独立パ

†第 11 回制御理論シンポジウムで発表（昭 $57 \cdot 5$ )

* 名古屋大学工学部 名古屋市千種区不老町

**東レ(株) 大津市園山 1-1-1

* Faculty of Engineering, Nagoya University, Nagoya

** Toray Inc., Otsu

(Received May 12, 1982)

(Revised September 13, 1982)
ラメータによる表現式）は既知であるが，独立パラメ 一タの值は未知であるとする線形構造化システムに対 し，その入出力応答（たとえば，伝達関数）から未知 の独立パラメータの值を，ほとんどすべての nominal value に対して, 局所的かつ一意的に決定するてとが できるかどうかという問題がある。 これは Bellman, Åström の提案した構造可同定性 ${ }^{12}$ の問題であり, Gloverの定義したパラメータ可同定性 ${ }^{2) ~ 4) ~ か ゙ ~ g e n e r i c ~}$ に成立するかどうかの問題である.

本論文では，非零固定要素が独立パラメー夕に関し て affine である 1 入力ー 1 出力線形構造化システム が構造可同定であるための新たな必要十分条件を与 え，てれをあとに，

（i）非零固定要素が互いに独立であるシステム (以後“一般の構造化システム”と呼ぶ)

(ii) 非零固定の移行係数が互いに独立であるコン パートメントシステム（以後単に“コンパートメント システム”と呼ぶ゙

の構造可同定性について考察する.

一般の構造化システムの構造可同定性に関しては, 著者らの知る限り，乙れまでまったく研究がなされて いない，本論文では，一般の構造化システムの構造可 同定性が，本質的に，システムの次元によって完全に 特微づけられることを示す。

コンパートメントシステムの構造可同定性に関して は，従来多くの研究がなされてきている ${ }^{5) ~ 8) ~ か ゙ ， そ の ~}$ 多くはシステムの構造に関する情報を構造可同定性の 問題の中に明確な形で取り込むととに成功しておら ず，その結果，構造可同定性の必要十分条件をシステ ムの構造上の表現に帰着させるという最終目的に程遠 いのが現状である. こうした中で, 前田ら ${ }^{8)}$ はシステ ムの構造上の変化 (流れの反転や漏れの有無). が構造 可同定性にどのような影響を与えるかを考察し, 興味 ある二，三の結果を与えている，てれに対し，本論文 ではサブシステム間の結合の仕方が全体のコンパート メントシステムの構造可同定性にどのような影響を与 
えるかを考察している。

\section{2. 構造可同定性と構造可制御・可観測性}

本論文で考察するシステムは，次式で記述される 1 入力ー 1 出力線形構造化システム $S$ である.

$$
S:\left\{\begin{array}{l}
\dot{\boldsymbol{x}}(t)=A(\boldsymbol{p}) \boldsymbol{x}(t)+\boldsymbol{b} u(t) \\
y(t)=\boldsymbol{c}^{T} x(t)
\end{array}\right.
$$

ここで, $\boldsymbol{x}(t) \in \boldsymbol{R}^{n}, v(t), y(t) \in \boldsymbol{R}$, 行列 $A(\boldsymbol{p})$ の非零 固定要素は独立パラメータを並べたべクトル $\boldsymbol{p}\left(\in \boldsymbol{R}^{r}\right)$ に関して affine であるとする.すなわち，

$$
A(\boldsymbol{p})=A(\mathbf{0})+\bar{A}(\boldsymbol{p}), \quad \bar{A}(\mathbf{0})=0
$$

であり, $\bar{A}(\boldsymbol{p})$ は $\boldsymbol{p}$ に関して線形である。また，

$$
\boldsymbol{b}=\boldsymbol{e}_{i}, \boldsymbol{c}=\boldsymbol{e}_{j}
$$

であるとし(ただし， $\boldsymbol{e}_{i}$ : 第 $i$ 単位べクトル), $i=j$ のとき, $S$ は D.P. (driving point) システム, $i \neq j$ のとき T. (transfer) システムと呼ばれる.

システム $S$ の伝達関数 $g(s, \boldsymbol{p})$ は,

$$
\begin{aligned}
& g(s, \boldsymbol{p}) \\
& \quad=\frac{\delta_{i j} s^{n-1}+b_{n-2}(\boldsymbol{p}) s^{n-2}+\cdots+b_{1}(\boldsymbol{p}) s+b_{0}(\boldsymbol{p})}{s^{n}+a_{n-1}(\boldsymbol{p}) s^{n-1}+\cdots+a_{1}(\boldsymbol{p}) s+a_{0}(\boldsymbol{p})}
\end{aligned}
$$

ただし

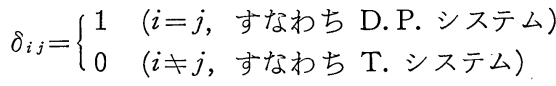

で与えられる。 こてで, $a_{n-1}(\boldsymbol{p}), \cdots, a_{0}(\boldsymbol{p}), b_{n-2}(\boldsymbol{p})$, $\cdots, b_{0}(\boldsymbol{p}) \in \boldsymbol{R}[\boldsymbol{p}]$ である. $\boldsymbol{R}[\cdot]$ は [ ]内の要素を 変数とするすべての実数係数多変数多項式の集合であ る.

\section{【定義 1】}

$\Gamma(\mathrm{i})$ ，システム $S$ が nominal value $\boldsymbol{p} \in \boldsymbol{R}^{r}$ で可同

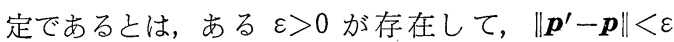
であり,

$$
g\left(s, \boldsymbol{p}^{\prime}\right)=g(s, \boldsymbol{p})
$$

ならば， $\boldsymbol{p}^{\prime}=\boldsymbol{p}$ となることである（ただし，\|・\|は 適当なノルムでよい).

（ii） システム $S$ が構造可同定であるとは，ある proper variety $V \subset \boldsymbol{R}^{\tau}$ が存在して, 任意の nominal value $\boldsymbol{p} \in \boldsymbol{R}^{r}-V$ で $S$ が可同定となることである.」

（注 1)（i）の可同定性は Grewal, Grover の定 義した局所パラメータ 可同定性 ${ }^{3)}$ と同一のむのであ る.

一方，Lin の定義した構造可制御（可観測）性 ${ }^{99} の$ 自然な拡張として, システムSの構造可制御性，構造 可観測性をつぎのように定義する。

\section{【定義 2】}

「システム $S$ が構造可制御（可観測）であるとは，あ
る proper variety $V \subset \boldsymbol{R}^{r}$ が存在して，任意の $\boldsymbol{p} \in$ $\boldsymbol{R}^{r}-V$ で, $(A(\boldsymbol{p}), \boldsymbol{b})\left(\left(\boldsymbol{c}^{T}, A(\boldsymbol{p})\right)\right)$ が可制御 (可観測) 対となることである.」

このとき，システム $S$ の構造可制御性，構造可観測 性之, (4) 式の伝達関数 $g(s, \boldsymbol{p})$ の分母 $a(s, \boldsymbol{p})$, 分 子 $b(s, \boldsymbol{p})$ ，すなわち

$$
\left\{\begin{aligned}
a(s, \boldsymbol{p})= & s^{n}+a_{n-1}(\boldsymbol{p}) S^{n-1}+\cdots+a_{1}(\boldsymbol{p}) s+a_{0}(\boldsymbol{p}) \\
b(s, \boldsymbol{p})= & \delta_{i j} s^{n-1}+b_{n-2}(\boldsymbol{p}) s^{n-2}+\cdots \\
& +b_{1}(\boldsymbol{p}) s+b_{0}(\boldsymbol{p})
\end{aligned}\right.
$$

との間につぎの補題が成り立つ.

\section{[補題 1]}

「システム $S$ が構造可制御かつ構造可観測であるため の必要十分条件は, $a(s, \boldsymbol{p}), b(s, \boldsymbol{p})(\in \boldsymbol{R}[s, \boldsymbol{p}])$ が $\boldsymbol{R}[s, \boldsymbol{p}]$ 上で共通 $s$-因子（ $s$ 亿関して次数が 1 次以 上の共通因子）をむたないととである.」

(証明) $a(s, \boldsymbol{p}), b(s, \boldsymbol{p})$ が $\boldsymbol{R}[s, \boldsymbol{p}]$ 上で共通's因子をあたないととと，ある proper variety $V \subset \boldsymbol{R}^{r}$ が存在して，任意の $\boldsymbol{p} \in \boldsymbol{R}^{r}-V$ で $a(s, \boldsymbol{p}), b(s, \boldsymbol{p})$ $(\in \boldsymbol{R}[s])$ が共通因子をむたないとととが等価である (たとえば,，文献 10), 補題 1) ので, 補題の主張は 明らかである。(証明終)

しかし，文献 14)でむ指摘されているように，シス テム $S$ が構造可同定であるためには，必らずしむ， $S$ が構造可制御かつ構造可観測であると必要はない.

そこで，本論文では，特に断わらない限り，システ ムSは構造可制御かつ構造可観測である必要はないむ のとする. したがって，(6)式の $a(s, \boldsymbol{p}), b(s, \boldsymbol{p})$ の $\boldsymbol{R}[s, \boldsymbol{p}]$ 上での最大共通因子を $h(s, \boldsymbol{p})$ とし，

$$
a(s, \boldsymbol{p})=h(s, \boldsymbol{p}) \bar{a}(s, \boldsymbol{p}), \quad b(s, \boldsymbol{p})=h(s, \boldsymbol{p}) \bar{b}(s, \boldsymbol{p})
$$

$$
\left\{\begin{aligned}
h(s, \boldsymbol{p})= & s^{m}+h_{m-1}(\boldsymbol{p}) s^{m-1}+\cdots+h_{1}(\boldsymbol{p}) s+h_{0}(\boldsymbol{p}) \\
\bar{a}(s, \boldsymbol{p})= & s^{n-m}+\bar{a}_{n-m-1}(\boldsymbol{p}) s^{n-m-1}+\cdots \\
& +\bar{a}_{1}(\boldsymbol{p}) s+\bar{a}_{0}(\boldsymbol{p}) \\
\bar{b}(s, \boldsymbol{p})= & \delta_{i j} s^{n-m-1}+\bar{b}_{n-m-2}(\boldsymbol{p}) s^{n-m-2}+\cdots \\
& +\bar{b}_{1}(\boldsymbol{p}) s+\bar{b}_{0}(\boldsymbol{p})
\end{aligned}\right.
$$

と書くことにする.

\section{《定理 1$\rangle$}

つぎの三つの条件は等価である.

（i） シズテム $S$ は構造可同定である.

(ii) g. $\operatorname{rank} \bar{J}(\boldsymbol{p})=r$

ただし， $\bar{J}(\boldsymbol{p})$ は，

$$
\bar{F}(\boldsymbol{p}) \triangleq\left(\bar{a}_{n-m-1}(\boldsymbol{p}), \cdots, \bar{a}_{0}(\boldsymbol{p}), \bar{b}_{n-m-2}(\boldsymbol{p}), \cdots, \bar{b}_{0}(\boldsymbol{p})\right)^{T}
$$

のヤコビ行列

$$
\bar{J}(\boldsymbol{p})=\frac{\partial \bar{F}(\boldsymbol{p})}{\partial \boldsymbol{p}}\left(\in \boldsymbol{R}[\boldsymbol{p}]^{(2 n-2 m-1) \times r}\right)
$$

であり, “g. rank”は generic rank を意味する. 
（iii) $\boldsymbol{q} \in \boldsymbol{R}[\boldsymbol{p}]^{r}$ に対して,

$$
\operatorname{det}\left[\begin{array}{ccc}
s I-A(\boldsymbol{p}) & 0 & \boldsymbol{b} \\
\bar{A}(\boldsymbol{q}) & s I-A(\boldsymbol{p}) & 0 \\
0 & \boldsymbol{c}^{T} & 0
\end{array}\right]=0
$$

ならば， $\boldsymbol{q}=0$ である。

あし，システムSが構造可制御かつ構造可観測であ れば，（i ），（ii ），（㧫)に加え，つぎの条件む等価であ る.

(iv) $X \in \boldsymbol{R}[\boldsymbol{p}]^{n \times n}, \boldsymbol{q} \in \boldsymbol{R}[\boldsymbol{p}]^{r}$ に対して,

$$
\left\{\begin{array}{l}
X A(\boldsymbol{p})-A(\boldsymbol{p}) X=\bar{A}(\boldsymbol{q}) \\
X \boldsymbol{b}=0 \\
\boldsymbol{c}^{T} X=0
\end{array}\right.
$$

ならば， $X=0, \boldsymbol{q}=0$ である.

(証明) $\quad(\mathrm{i}) \Leftrightarrow($ ii $)$ : 仮定より, $\bar{a}(s, \boldsymbol{p}), \bar{b}(s, \boldsymbol{p})$ は $\boldsymbol{R}[s, \boldsymbol{p}]$ 上で共通 $s$-因子をあたず，したがって，ある proper variety $V \subset \boldsymbol{R}^{r}$ が存在して, ${ }^{\forall} \boldsymbol{p} \in \boldsymbol{R}^{r}-V$ で, $\bar{a}(s, \boldsymbol{p}), \bar{b}(s, \boldsymbol{p})(\in \boldsymbol{R}[s])$ は共通因子をあたない。ゆ えに, nominal value として任意の $\boldsymbol{p} \in \boldsymbol{R}^{r}-V$ を考

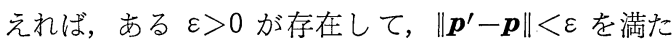
す任意の $\boldsymbol{p}^{\prime}$ が $\boldsymbol{p}^{\prime} \in \boldsymbol{R}^{r}-V$ とするととができ, $\bar{a}(s$, $\boldsymbol{p}), \bar{b}(s, \boldsymbol{p})(\in \boldsymbol{R}[s])$ は共通因子をむたず, $\bar{a}\left(s, \boldsymbol{p}^{\prime}\right)$, $\bar{b}\left(s, \boldsymbol{p}^{\prime}\right)(\in \boldsymbol{R}[s])$ む共通因子をむたないととになる.

さて, (5) 式は $\bar{a}(s, \boldsymbol{p}) \bar{b}\left(s, \boldsymbol{p}^{\prime}\right)=\bar{a}\left(s, \boldsymbol{p}^{\prime}\right) \bar{b}(s, \boldsymbol{p})$ と 等価であり，上述のととから， $\bar{a}(s, \boldsymbol{p})=\bar{a}\left(s, \boldsymbol{p}^{\prime}\right), \vec{b}(s$, $\boldsymbol{p})=\bar{b}\left(s, \boldsymbol{p}^{\prime}\right)$, つまり $\bar{F}\left(\boldsymbol{p}^{\prime}\right)=\bar{F}(\boldsymbol{p})$ と等価である.

以上のとと加ら，条件 (i )と（ii）の等価性は，陰関 数・逆関数の定理 ${ }^{11)}$ より明らかである.

(ii) $\Leftrightarrow($ iil ) :

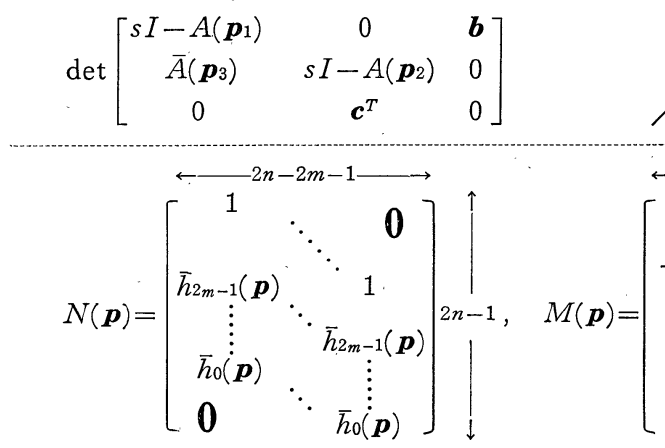

$\searrow \quad=\left(s^{2 n-2}, s^{2 n-3}, \cdots, s, 1\right) G\left(\boldsymbol{p}_{1}, \boldsymbol{p}_{2}\right) \boldsymbol{p}_{3}$

(ただし， $\left.G\left(\boldsymbol{p}_{1}, \boldsymbol{p}_{2}\right) \in \boldsymbol{R}\left[\boldsymbol{p}_{1}, \boldsymbol{p}_{2}\right]^{(2 n-1) \times r}\right)$ と書くことが できることから, 条件 (恧)と g. $\operatorname{rank} G(\boldsymbol{p}, \boldsymbol{p})=r$ と は等価である.

一方,

$$
\begin{aligned}
& \frac{b\left(s, \boldsymbol{p}^{\prime}\right)}{a\left(s, \boldsymbol{p}^{\prime}\right)}-\frac{b(s, \boldsymbol{p})}{a(s, \boldsymbol{p})} \\
& \quad=\boldsymbol{c}^{T}\left(s I-A\left(\boldsymbol{p}^{\prime}\right)\right)^{-1} \boldsymbol{b}-\boldsymbol{c}^{T}(s I-A(\boldsymbol{p}))^{-1} \boldsymbol{b} \\
& \quad=\left(\begin{array}{ll}
0 & \boldsymbol{c}^{T}
\end{array}\right)\left(\begin{array}{cc}
s I-A(\boldsymbol{p}) & 0 \\
-\bar{A}\left(\boldsymbol{p}^{\prime}-\boldsymbol{p}\right) & s I-A\left(\boldsymbol{p}^{\prime}\right)
\end{array}\right)^{-1}\left(\begin{array}{l}
\boldsymbol{b} \\
0
\end{array}\right)
\end{aligned}
$$

より,

$$
\begin{aligned}
b & \left(s, \boldsymbol{p}^{\prime}\right) a(s, \boldsymbol{p})-b(s, \boldsymbol{p}) a\left(s, \boldsymbol{p}^{\prime}\right) \\
& =\operatorname{det}\left(\begin{array}{ccc}
s I-A(\boldsymbol{p}) & 0 & \boldsymbol{b} \\
\bar{A}\left(\boldsymbol{p}^{\prime}-\boldsymbol{p}\right) & s I-A\left(\boldsymbol{p}^{\prime}\right) & 0 \\
0 & \boldsymbol{c}^{T} & 0
\end{array}\right) . \\
& =\left(s^{2 n-2}, s^{2 n-3}, \cdots, s, 1\right) G\left(\boldsymbol{p}, \boldsymbol{p}^{\prime}\right)\left(\boldsymbol{p}^{\prime}-\boldsymbol{p}\right)
\end{aligned}
$$

であり，したがって，

$$
\begin{gathered}
\frac{\partial b(s, \boldsymbol{p})}{\partial \boldsymbol{p}} a(s, \boldsymbol{p})-b(s, \boldsymbol{p}) \frac{\partial a(s, \boldsymbol{p})}{\partial \boldsymbol{p}} \\
\quad=\left(s^{2 n-2}, \cdots, s, 1\right) G(\boldsymbol{p}, \boldsymbol{p})
\end{gathered}
$$

を得る.とこで,

\section{(14) 式の左辺}

$$
\begin{aligned}
& =h^{2}(s, \boldsymbol{p})\left(\bar{a}(s, \boldsymbol{p}) \frac{\partial \bar{b}(s, \boldsymbol{p})}{\partial \boldsymbol{p}}-\bar{b}(s, \boldsymbol{p}) \frac{\partial \bar{a}(s, \boldsymbol{p})}{\partial \boldsymbol{p}}\right) \\
& =\left(s^{2 n-2}, s^{2 n-3}, \cdots, s, 1\right) N(\boldsymbol{p}) M(\boldsymbol{p}) \bar{J}(\boldsymbol{p})
\end{aligned}
$$

ただし，

$$
h^{2}(s, \boldsymbol{p})=s^{2 m}+\bar{h}_{2 m-1}(\boldsymbol{p}) s^{2 m-1}+\cdots+\bar{h}_{1}(\boldsymbol{p}) s+\bar{h}_{0}(\boldsymbol{p})
$$
と書けば
であるので, 結局, $N(\boldsymbol{p}) M(\boldsymbol{p}) \bar{J}(\boldsymbol{p})=G(\boldsymbol{p}, \boldsymbol{p})$ を得 る. (15)式から $N(\boldsymbol{p})$ は column full rank であり, また仮定 $(\bar{a}(s, \boldsymbol{p}), \bar{b}(s, \boldsymbol{p})$ は $\boldsymbol{R}[s, \boldsymbol{p}])$ 上で共通 $s$ 因子をむたないてと）加ら $M(\boldsymbol{p})$ は generic に正則 である。

以上より, g. $\operatorname{rank} \bar{J}(\boldsymbol{p})=\mathrm{g} \cdot \operatorname{rank} G(\boldsymbol{p}, \boldsymbol{p})$ であり, 条件 (ii)と（並)の等分性を示すととができた.
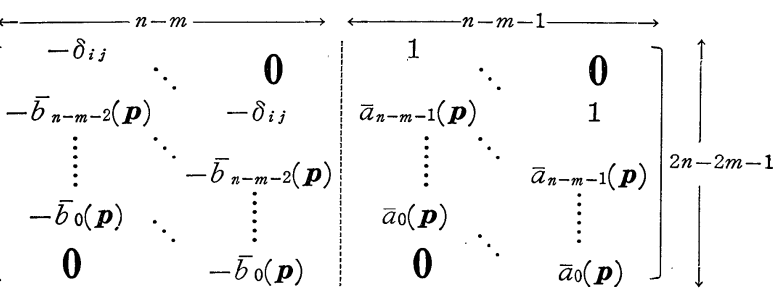

(15) に対して，条件 (iii) と（iv)の等価性を示す.

(iii) $\Rightarrow$ (iv)：ある $X \in \boldsymbol{R}[\boldsymbol{p}]^{n \times n}, \boldsymbol{q} \in \boldsymbol{R}[\boldsymbol{p}]^{r}$ で (12) 式が成立したとする，乙のとき，(12.a)式から

$$
\begin{aligned}
& (s I-A(\boldsymbol{p}))^{-1} \bar{A}(\boldsymbol{q})(s I-A(\boldsymbol{p}))^{-1} \\
& \quad=X(s I-A(\boldsymbol{p}))^{-1}-(s I-A(\boldsymbol{p}))^{-1} X
\end{aligned}
$$

が成り立ち，(12.b)，(12.c)式を用いて， 


$$
\boldsymbol{c}^{T}(s I-A(\boldsymbol{p}))^{-1} \bar{A}(\boldsymbol{q})(s I-A(\boldsymbol{p}))^{-1} \boldsymbol{b}=0
$$

を得る. (16)式は(11) 式と等価であり, 結局 $\boldsymbol{q}=0$ を 得る、 $\boldsymbol{q}=0$ を(12.a)式に代入し，(12.b)式を用いる と, $X\left[\boldsymbol{b}, A(\boldsymbol{p}) \boldsymbol{b}, \cdots, A(\boldsymbol{p})^{n-1} \boldsymbol{b}\right]=0$. 仮定（構造可制 御性) より， $X=0$ を得る.

(iv) $\Rightarrow$ (iii)：ある $\boldsymbol{q} \in \boldsymbol{R}[\boldsymbol{p}]^{r}$ に対して, (11)式が 成立したとする.

$$
\begin{aligned}
& \hat{A} \triangleq\left(\begin{array}{cc}
A(\boldsymbol{p}) & 0 \\
-\bar{A}(\boldsymbol{q}) & A(\boldsymbol{p})
\end{array}\right), \quad \hat{\boldsymbol{b}} \triangleq\left(\begin{array}{l}
\boldsymbol{b} \\
0
\end{array}\right), \quad \hat{\boldsymbol{c}} \triangleq\left(\begin{array}{l}
0 \\
\boldsymbol{c}
\end{array}\right) \\
& \mathcal{C} \triangleq\left(\hat{\boldsymbol{b}}, \hat{A} \hat{\boldsymbol{b}}, \cdots, \hat{A}^{n-1} \hat{\boldsymbol{b}}\right)=\left(\begin{array}{l}
\boldsymbol{b}, A(\boldsymbol{p}) \boldsymbol{b}, \cdots, A(\boldsymbol{p})^{n-1} \boldsymbol{b} \\
0, \\
\hdashline
\end{array}\right) \\
& \triangleq\left(\begin{array}{c}
\stackrel{n}{C_{n}} \\
-U
\end{array}\right) \uparrow n
\end{aligned}
$$

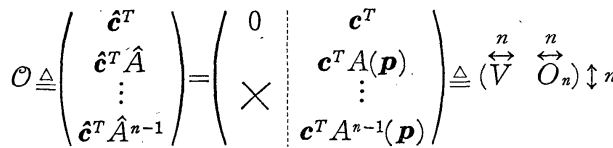

と置けば，(11)式は $\hat{\boldsymbol{c}}^{T}(s I-\hat{A})^{-1} \hat{\boldsymbol{b}}=0$ と等価であり， ゆえに，

$$
\left\{\begin{array}{lr}
\mathcal{O C}=V C_{n}-O_{n} U=0 & (17 . \mathrm{a}) \\
\mathcal{O A C}=V A(\boldsymbol{p}) C_{n}-O_{n} A(\boldsymbol{p}) U-O_{n} \bar{A}(\boldsymbol{q}) C_{n}=0 \\
\end{array}\right.
$$

を得る.とこで,

$$
\begin{aligned}
& \alpha \triangleq \operatorname{det} O_{n} \cdot \operatorname{det} C_{n}(\neq 0) \in \boldsymbol{R}[\boldsymbol{p}], \\
& X \triangleq \alpha O_{n}{ }^{-1} V \in \boldsymbol{R}[\boldsymbol{p}]^{n \times n}
\end{aligned}
$$

と置き， $\alpha \boldsymbol{q}$ を改めて $\boldsymbol{q}\left(\in \boldsymbol{R}[\boldsymbol{p}]^{r}\right)$ と置けば，(17.a) 式から $X=\alpha U C_{n}{ }^{-1}$ であり，(17.b)式から (12.a)式 を得る。ささらに，

$$
\left\{\begin{array}{l}
X \boldsymbol{b}=\alpha U C_{n}^{-1} \boldsymbol{b}=\alpha U \boldsymbol{e}_{1}=0 \\
\boldsymbol{c}^{T} X=\alpha \boldsymbol{c}^{T} O_{n}{ }^{-1} V=\alpha \boldsymbol{e}_{1}{ }^{T} V=0
\end{array}\right.
$$

より，(12.b)，(12.c)式を得る.したがって, $\boldsymbol{q}=0$ である。(証明終)

(注 2) 条件 (ii ) は, $F(\boldsymbol{p})=\left(a_{n-1}(\boldsymbol{p}), \cdots, a_{0}(\boldsymbol{p})\right.$, $\left.\boldsymbol{b}_{n-2}(\boldsymbol{p}), \cdots, b_{0}(\boldsymbol{p})\right)^{T}$ のヤコビ行列の column full rank 性,すなわち,

$$
J(\boldsymbol{p})=\frac{\partial F(\boldsymbol{p})}{\partial \boldsymbol{p}} \in \boldsymbol{R}[\boldsymbol{p}]^{(2 n-1) \times r}
$$

に対して g. $\operatorname{rank} J(\boldsymbol{p})=r$ という条件と等価でない. 二般に g. $\operatorname{rank} J(\boldsymbol{p}) \geq \mathrm{g} . \operatorname{rank} \bar{J}(\boldsymbol{p})$ であるので注意 を要する.

（注 3）条件（iv）は，文献 2）でクロネッカ積の表 現で与えられている条件が generic に成立すること と同じことである。

\section{3. 一般の構造化システムとコンパートメ ントシステムの構造可同定性}

この章では，前章，定理 1 をむとに，一般の構造化 システムやコンパートメントシステムの構造可同定性 をシステムのグラフ構造との関係から考察する.

\section{1 一般の構造化システムの構造可同定性}

(1)式において，行列 $A(\boldsymbol{p})$ の非零固定要素がすべ て互いに独立なパラメータであるとき，システム $S$ を 一般の構造化システムと呼ぶことにする.

一般の構造化システム $S$ では，行列 $A(\boldsymbol{p})$ のすべて の非零固定要素を並べたベクトルを $\boldsymbol{p} \in \boldsymbol{R}^{r}$ とするこ とができ，したがって，(2)式において， $A(0) \nRightarrow O$, $\bar{A}(\boldsymbol{p})=A(\boldsymbol{p})$ である.

$n$ 次元の一般の構造化システム $S$ のシステム構造は 一つの入力節点, 一つの出力節点, および $n$ 個の状態 節点をむつ Coates グラフ ${ }^{9}$ で表現するととができ る. この Coates グラフの強連結成分のうち，自己ル ープをむたないただ一つの状態節点だけからなる強連 結成分を零節点と呼ぶことにする，また，強連結成分 で入力節点からのパスおよび出力節点へのパスがとも に存在するむのは入出力連結であると呼ぶことにす る.

\section{[補題 2]}

一般の構造化システム $S$ が構造可同定であるために は,その Coates“グラフに㨟いて，入出力連結でない強 連結成分は孤立した零節点だけでなければならない。」

（証明） 入出力連結でない強連結成分 $D$ が零節点で なければ，D含まれる有向枝(少なくとも一つ存在) に対応する $\boldsymbol{p}$ の要素は (8) 式の $h(s, \boldsymbol{p})$ に含まれ， $\bar{a}(s, \boldsymbol{p})$ や $\bar{b}(s, \boldsymbol{p})$ には含まれない $(a(s, \boldsymbol{p}), b(s, \boldsymbol{p})$ は $\boldsymbol{p}$ の各要素に関して1次以下である).したがって， 定理 1 , 条件 (ii) 満たされず，構造可同定になり得 ない.

一方，入出力連結でない強連結成分が零節点ではあ るが，孤立していないとする，乙のとき，その零節点 は少なくとも一つの入枝加出枝をすつととになるが, それらに対応する $\boldsymbol{p}$ の要素は(6)式の $a(s, \boldsymbol{p}), b(s$, p) に現れず，したがって，定理 1 ，条件（ii)が満た されない.ゆえに，乙の場合も構造可同定になり得な い. (証明終)

この補題から，すべての強連結成分が入出力連結で ある一般の構造化システムだけを考えればよいことに なる。

《定理 2》

Coates グラフのすべての強連結成分が入出力連結 


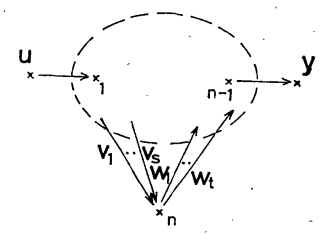

Fig. 1 Coates graph

である一般の構造化システムSにおいて,

(i) シズテムの次元が 2 次以上の D.P. システム は構造可同定になり得ない。

（ii） システムの次元が 3 次以上の T. システムは 構造可同定になり得ない.」

(証明) $n(\geq 3)$ 次元の T. システムでは, 一般性 を失うことなく，(1)式において，

$$
A(\boldsymbol{p})=\left(\begin{array}{lr}
A_{11} & \boldsymbol{w} \\
\boldsymbol{v}^{T} & a_{22}
\end{array}\right) \uparrow_{\uparrow 1}^{\uparrow n-1}, \underset{1}{\leftrightarrow}, \quad \boldsymbol{b}=\boldsymbol{e}_{1}, \quad \boldsymbol{c}=\boldsymbol{e}_{n-1}
$$

としてよい(Fig. 1). ここで, $\boldsymbol{v}$ は $v_{1}, v_{2}, \cdots, v_{s}$ と 零固定要素加, $\boldsymbol{w}$ は $w_{1}, w_{2}, \cdots, w_{t}$ 亡零固定要素 からなるべクトルであり (仮定から， $s, t \geq 1), A_{11}$, $a_{11}$ に含まれるpの要素からなるべクトルを $\tilde{\boldsymbol{p}}$ とすれ ば, $\boldsymbol{p}=\left(v_{1}, \cdots, v_{s}, w_{1}, \cdots, w_{t}, \tilde{\boldsymbol{p}}^{T}\right)^{T}$ である.

定理 1, 条件 ( $\left.w_{1}, \cdots, w_{t}, 0 \cdots 0\right)^{T}(\neq 0) \in \boldsymbol{R}[\boldsymbol{p}]^{r}$ を考えれば，

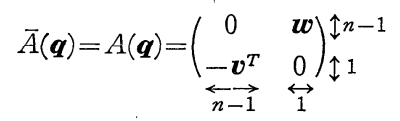

であり，したがって簡単な計算から，(11)式が成り立 つととがわかる. ゆえに，構造可同定でないととを示 すととができた。

$n(\geq 2)$ 次元の D. P. システムについても同様に構 造可同定でないことを示すことができる.（証明終）

定理 2 から，構造可同定な一般の構造化システムの Coates グラフ構造をすべて挙げるととができ，孤立 した零節点を除けば，Fig. 2 に示す 9 種類である。

\section{2 コンパートメントシステムの構造可同定性}

$n$ 個のコンパートメントからなり， $i$ 番目のコンパ 一トメントを入カコンパートメント， $j$ 番目のコンパ 一トメントを出力コンパートメントとするコンパート メントシステムを考える. 非零固定の移行係数 $k_{i j}($ : $j$ 番目のコンパートメントから $i$ 番目のコンパートメ ントへの移行係数) や $k_{0 j}$ ( : $j$ 番目のコンパートメン トから系外への漏れの移行係数) が互いに独立なパラ メータとみなすととができれば，乙れらすべての非零 固定の移行係数を並べたベクトル $\boldsymbol{p} \in \boldsymbol{R}^{r}$ を用いて, コンパートメントシステムは (1)式で記述される。た だし，(2)式において， $A(0)=O, \bar{A}(\boldsymbol{p})=A(\boldsymbol{p})$ であ

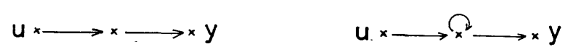

(a ) D.P. systems

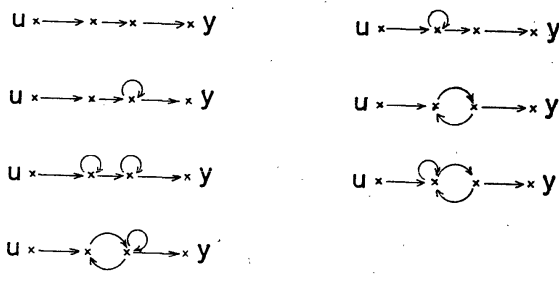

(b) T. systems

Fig. 2 All the structured systems that are structurally identifiable

り, $A(\boldsymbol{p})$ の $(i, j)$ 要素 $a_{i j}$ は

$a_{j i}=k_{i j}(i \neq j), \quad a_{i i}=-k_{0 i}-\sum_{\substack{j=1 \\ j \neq i}}^{n} k_{j i}$

である ${ }^{12)}$. したがって， $i$ 番目のコンパートメントが 漏れをむたなければ $\left(k_{0 i}=0\right), \sum_{j=1}^{n} a_{i j} \equiv 0$ である. 行 列 $A(\boldsymbol{p})$ の非零固定要素のとの従属性により, コン パートメントシステムでは，もはや定理 2 が成立しな い.

コンパートメントシステムのシステム構造を表現す るコンパートメントグラフの強連結成分は，ほかの強 連結成分間との流入出枝の有無によって, ソース, ト ランジット，シンクに分類される ${ }^{12)}$. 孤立した強連結 成分は定義よりソースとあシンクとあ考えられる12) が，ここではシンクと考えることにする．特に，漏れ をあたないシンクはトラップと呼ばれる年. ここで は，ただ一つのコンパートメントからなるトラップを 単純トラップと呼ぶことにする.したがって単純卜ラ ップには，ほかの強連結成分からの流入枝をむつ単純 トラップと孤立した単純トラップがあるととになる.

\section{[補題 3]}

「コンパートメントシステムが構造可同定であるため には，そのコンパートメントグラフにおいて，入出力 連結でない強連結成分は単純トラップだけでなければ ならない.」

（証明）補題 2 とほぼ同様に示すととができるの で略す.

(証明終)

\section{[補題 4]}

コンパートメントグラフ $G_{c}$ で表現されるコンパー トメントシステム $S$ を考える. $G_{c}$ の入出力連結でな いすべての単純トラップを取り除き, 単純トラップヘ の流入枝を漏れとする（したがって，一つのコンパー トメントが複数の漏れをむつ場合があるが; 複数の漏 れのままとする) ととによってできるコンパートメン 


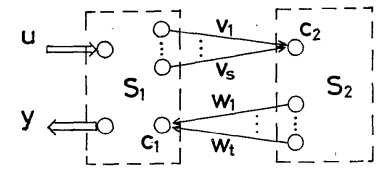

Fig. 3 Compartmental system consisting of. subsystems $S_{1}$ and $S_{2}$

トグラフ $\bar{G}_{c}$ で表現されるコンパートメントシステム を $\bar{S}$ とする．乙のとき， $S$ と $\bar{S}$ の構造可同定性は等 価である.」

(証明) $S$ と $\bar{S}$ 亿対して，（8)式の $\bar{a}(s, \boldsymbol{p}), \bar{b}(s, \boldsymbol{p})$ は同一であり, したがって, 定理 1 の条件 (ii)より, 補題の主張は明らかである。(証明終)

補題 3，4 により, コンパートメントシステムの構 造可同定性を考察する場合, 本質的には, 入出力連結 なコンパートメントグラフ構造だけを考えれば十分で あることがわかる。

そこで，つぎに，サブシステム間の結合の仕方が全 体のコンパートメントシステムの構造可同定性にどの ような影響を与えるかを考察する。

まず最初に，容易に推察できるつぎの定理を挙げる ことができる。

《定理 3$\rangle^{133,15)}$

「Fig. 3 のコンパートメントグラフで表現されるコ ンパートメントシステムを考える. ここで入出カコン パートメントは $S_{1}$ に含まれ， $S_{1}$ 加ら $S_{2}$ への流出枝 $v_{1}, \cdots, v_{s}$ の終点は $C_{2}, S_{2}$ 加 $S_{1}$ への流出枝 $w_{1}$, $\cdots, w_{t}$ の終点は $C_{1}$ であるとする．乙のとき， $C_{2}$ を 入力コンパートメント， $C_{1}$ を出カコンパートメント とするサブシステム $\tilde{S}_{2}$ (ただし， $C_{1}$ からの流出枝 は，漏れを含め，すべて取り除く）が構造可同定でな ければ，全体のコンパートメントシステムは構造可同 定になり得ない.」

(注 4) 文献 13)では，あるクラスのコンパートメ ントシステムに限って, 定理 2 と同様のととが述べら れている. また，定理 3 と対応する結果が文献 15)で 示されているが, そこではサブシステム $\tilde{S}_{2}$ の意味が 明確でないので，乙てで定理 3 として挙げておく。な お，定理 3 の証明は，文献 15) と異なり, 定理 1 の条 件（iii）を用いて示すととができるが，乙こでは省略す る.

\section{さらに，つぎの定理が成り立つ。}

\section{《定理 4 》}

「Fig. 4 のコンパートメントグラフで表現されるコ ンパートメントシステムを考える. こてで入出カコン パートメントはサブシステム $S_{1}$ に含まれ $S_{1}$ から $S_{2}$

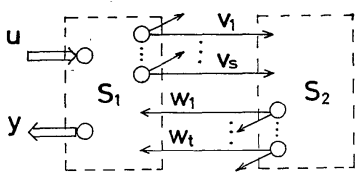

Fig. 4 Unidentifiable structure of compartmental systems

への流出枝 $v_{1}, \cdots, v_{s}$ および $S_{2}$ から $S_{1}$ への流出枝 $w_{1}, \cdots, w_{t}$ をむつコンパートメントはすべて漏れをむ つあのとする．乙のとき，全体のコンパートメントシ ステムは構造可同定になり得ない.」

(証明) $n\left(S_{1}: n_{1}\right.$ 次元, $S_{2}: n_{2}$ 次元, $\left.n=n_{1}+n_{2}\right)$ 次元の T. システムを考える.

一般性を失うことなく，入力コンパートメントを 1 番目, 出力コンパートメントを $n_{1}$ 番目としてよい. とのとき,

$$
A(\boldsymbol{p})=\left(\begin{array}{ll}
A_{1} & W \\
V & \stackrel{A_{2}}{V}
\end{array}\right) \underset{\uparrow n_{1}}{\stackrel{\leftrightarrow}{n_{2}}}
$$

であり, $V$ は $v_{1}, \cdots, v_{s}$ 之零固定要素, $W$ は $w_{1}, \cdots$, $w_{t}$ 之零固定要素からなる行列である.

仮定から， $v_{1}, \cdots, v_{s}$ および $w_{1}, \cdots, w_{t}$ の始点のコ ンパートメントは漏れをむつので, 定理 1 の条件 (iii) の $\boldsymbol{q}$ として,

$$
A(\boldsymbol{q})=\left(\begin{array}{cc}
0 & W \\
-V & 0
\end{array}\right)
$$

なる $\boldsymbol{q}(\neq 0) \in \boldsymbol{R}[\boldsymbol{p}]^{r}$ が存在する，しかも，簡単な計 算から，乙の $\boldsymbol{q}$ 亿対して(11)式が成立することがわ かる. 沛えに，構造可同定になり得ないととを示すと とができた。

D. P. システムの場合む同様に示すととができる.

(証明終)

\section{4. あとがき}

本論文では, 非零固定要素が独立パラメータに関し て affine である 1 入力ー 1 出力構造化システムが構 造可同定であるための代数的必要十分条件を新たに与 え，乙れをあとに，グラフ構造的見地から，一般の構 造化システムとコンパートメントシステムの構造可同 定性を考察した

本論文での考察により, 構造可同定な一般の構造化 システムをすべて挙げるてとができた，また，コンパ ートメントシステムの構造可同定性汇関しては, 本質 的に入出力連結なコンパートメントグラフ構造だけを 考えれば十分であること，サブシステム間の結合の仕 方が全体のシステムに及ぼす若干の性質等を明らかに するととができた. 


\section{参 考 文 献}

1) R. Bellman and K. J. Åström: On Structural Identifiability, Math. Bios., 7, 329/339 (1970)

2) K. Glover and J.C. Willems: Parametrizations of Linear Dynamical Systems; Canonical Forms and Identifiability, IEEE Trans. on Automatic Control AC-19-6, 640/646 (1974)

3) M.S. Grewal and K. Glover: Identifiability of Linear and Nonlinear Dynamical Systems, IEEE Trans. on Automatic Control AC-21-6, 833/837 (1976)

4) 丹羽: 線形定係数系の可同定性, 計測自動制御学会論文 集, 16-2, 195/202 (1980)

5) M. Millanese and N. Sorrentino: Decomposition Methods for the Identifiability Analysis of Large Systems, International. J. of Control, 28-1, 71/79 (1978)

6) C. Cobelli, A. Lepschy and G. Roman-Jacur: Identifiability of Compartmental Systems and Related Structural Properties, Math. Bios., 44, 1/18 (1979)

7) J. Delforge: Necessary and Sufficient Structural
Condition for Local Identifiability of a System with Linear Compartments, Math. Bios., 54, 159/ 180 (1981)

8) 前田, 他：コンパートメントシステムの構造可同定性と グラフ構造，計測自動制御学会論文集， 17-4，455/460 (1981)

9) C. T. Lin: Structural Controllability, IEEE Trans on Automatic Control AC-19-3, 201/208 (1974)

10)早川, 他：線形時不変コンパートメントシステムの構造 可制御性，信学論， J 65-A-4, 371/378 (1982)

11) 高木：解析概論, p. 296, 岩波書店 (1971)

12) 前田：コンパートメントシステムの構造と特性, 計測と 制御, 20-7, 713/719 (1981)

13) 岡野, 他: コンパートメントシステムの構造可同定性に 関する一考察, 信学論, J 64-A-3, 203/210 (1981)

14) J. J. Distefano: On the Relationships between Structural Identifiability and the Controllability, Observability Properties, IEEE Trans. on Automatic Control AC-22-4, 652 (1977)

15）岡野, 他：線形時不変コンパートメントシステムの構造 可同定性，第 2 回 Dynamical System Theory シンポ ジウム資料，39/44 (1979) 